included. Pigmentation alone is not sufficient. Many cuses described as Addison's disease run a very chronic course with few or no symptoms and a normal blood pressure. In one of Janeway's it was even raised. He does not say if pigmentation was present. Extensive tuberculous lesions involving, amongst other organs, the adrenals were found post mortem. But we must remember that Addison's disease may not be present even with somewhat advanced adrenal lesions, because macroscopic change is a very inadequate test of chemical function. Boinet describes, with surprise, a case of extensive lesions of both adrenals with no symptoms. There was also contracted granular kirney, which may have counteracted any deficiency of adrenalin by raising the blood pressure.

Summary.-1. The symptoms of Addison's disease are due to vaso-motor paralysis. This is due to absence of adrenalin, the normal excitant of the sympathetic nerve endings, from the blood. 2. The pigmentation is due to vascular relaxation of the skin cansing exaggerated functional activity of the pigment cells. 3. The moxt promising line of treatment, on theoretical grounds, is the administration of vasoconstrictors of prolonged action and digitalin has given good results in one case.

Postscript.-The subsequent history of this patient was extremely disapp rinting. Towards the end of January he met with a slight accident, which apparently turned the delicately poised scale against him and be became rapidly worse and died in February, 1906. I unfortunately was not able to see him during this time, having left the hospital, nor did I see the necropsy, but the pathologist kindly informed me that the suprarenal glands showed extreme atrophy but no tuberculosis and there was old tuberculous mischief of mild degree at the left apex of the left lung. There were no other lesions.

Billiography.-This is not meant to be a full bibliography of Addison's disease or the suprarenals. Such may be found in Allbutt's System and in Vecchi's article. The following are merely the authorities quoted: I Abelous: Comptes Rendus de la Société de Biologie, Paris, 1904, lvi, p. 952. 2 Addison: Disease of the Suprarenal Capsules, 1855. 3 Boinet: De l'Addisonisme, Archives Générales de Médecine, Paris, 1904, ii.. p. 2324. 4 B. Bramwell: Clinical Studies, Edinhurgh, 1903-04, New Series, vol. ii., p. 142.5 Conder Edinburgh Medical Journal, 1905, p. 275. "6 Garrod: Journal of Physiology, vol. xiii., p. 598; Brit. Med Jour., 1895, vol. i., p. 747. 7 Greenhow: Croonian Lectures, 1875. 8 Harlev: British and Foreign Medico-Chirurgical Review, vol. xxi., p. 204.9 Janewav: The Clinical Studv of Blood Pressure, New York. 1904. 10 Langley: Journal of Physiology, 1901, p. 236. 11 MacM unn Brit Med. Jour., 1886, vol. i., p. 31 ; Philosophical Trankactions, 1886. 12 Marino-Zucco : Riforma Medica, Rome, 1892, tome i. 13 Nothnagel Zeitschrift fir Klinische Medicin, Berlin, 1879, Band i, S 77. 14 Oliver and Schäfer; Journal of Physiology, 1895 p 202 15 Pföringer and Schafer; Journal of Physiologv, 1895, $p$ 202. 15 Ploringer 1900, S. 1. 16 Potain: La Pression Arterielle de l'Homme à l'état 1900, S. 1, 16 Potain: La Pression Arterielle de l'Homme à l'éta Normal et Patholngique. Paris, 1902. ' 7 Rolleston: Allbutt's Svstem vol. iv., 1897; Encyclol ædia of Medicine, vol. i.. 1899. 18 Tizzoni : Allgemeine Pathologie und Pathologische Anatomie, 1901, S. 577.

\section{THE APPOINTMENT OF QUALIFIED WOMEN WITH SPECIAL REFER- ENCE TO THE HYGIENE AND FEEDING OF INFANTS.}

By J. SPOTTISWOODE CAMERON, M.D., B.Sc. EdIN., MEDICAL OFFICER OF HEALTH OF LEEDS.

"Women as Sanitary Inspectors" was the title of a paper which was read by me in Exeter in August, 1902, and which appeared in the Journal of State Medicine in December of the same year. The subject was one, however, which had interested me for many years before. I had frequently talked it over with Dr. J. F. W. Tatham when the latter was medical officer of Salford, and later still of Manchester, before he went to the important post he now holds in the Registrar-General's office. The matter was indeed brought from time to time conversationally before the chairman of the Leeds Sanitary Committee, but it was not till about 1897 that the committee itself was prepared to act upon the suggestions previously made. The women's conference of the Congress of the Royal Sanitary Institute held that year in Leeds passed resolution which was sent to the sanitary committee and at the November meeting I was asked to report on what particular duties might be allocated to a woman inspector if one were appointed. In my report, dated Dec $9 \mathrm{th}, 1897$, it was suggested that if one woman inspector only were appointed she would be specially charged with the dutv of visiting workshops where women are employed. Her duties in regard to these work-places would be those of the ordinary workshop inspector, to watch over their cleanliness and ventilation, to prevent their being overcrowded, and to secure that no effluvium should enter the work-places from their drains or conveniences. The report entered somew hat into detail as to duties. It was further suggested that if the committee resolved to appoint several inspectors one or more of them should be told off to visit bouses where children under two years of age had died, except where these deaths were already being investigated in the ordinary way in connexion with zymotic inquiries. The report then went on to remark that its infantile mortality is an important indication of the health of a town and that it had in Leeds for many years back been unfortunately high. It was suggested that the woman inspector "should make a complete examination of the house and the outside evidences as to the state of its drainage, if necessary obtaining the assistance of the ward inspector" in testing the latter. It was pointed out that "one principal advantage of her visit would be her oversight of the condition of the house in regard to cleanliness, the treatment of the chilcren in regard to diet, and what might be called the romestic part of hygiene as distinguished from that part of hygiene which is more connected with sanitary appliances, so-called. She would be expected to be able to advise mothers what symptoms to be on the look-out for when infective disease was in the neighbourhood and to have a sufficient knowledge of the early symptoms of infantile diseases to instruct the more ignorant among them in regard to those slight cases of infectious disease which are so exceeringly apt to be neglected and to lead to the infection of other members of the family. She would advise the woman of the house as to the way to keep the trapped gullies about the premises clean and the importance of doing so." She would also, it was hoped, " exercise her influence in persuading the housewife not to throw large quantities of vegetable and animal garbage into the dustbin." The report went on to say : "In going over the reports by the ward inspectors it has often struck me that there is considerable variation in regard to the returning of the bouses they visit as 'clean' or 'dirty.' The addition of trained women to our staff of inspectors would probably raise the standard in this matter. Their advice to housewives upon the place for keeping food, and especially milk, upon the necessity for scalding the latter, esper ially in hot weather, their instructions as to the thorocgh cleansing and disinfection of the feeding bottle, would all be of great value as preventatives of infantile disease." This report was printed and circulated in January, 1898, and was followed by a further one, printed in March of the same year, and reprinted in the following February, setting forth the results of it quiries made in several other towns as to the women there employed as sanitary inspectors. It was found that the amounts paid varied even in Manchester from 14s. a week to "health visitors" up to $37 s$. $6 d$. for the trained workshops inspectors.

In the year last named the Leeds Stnitary Committee resolved to appoint two women as assistant inspectors, the qualification to be the same as for the men-the inspector's certificate of the Royal Sanitary Institute or that of the London or Scotch Boards. They also resolved that the salary should begin, like that of the men, at $33 \mathrm{~s}$. a week. We were exceedingly fortunate in our first appointments. Two ladies of considerable attainments, both holding the certificate of the Royal Sanitary Institute and both enthusiasts in regard to the work, were appointed towards the end of May in that year. At first their duiles consisted largely of workshops inspection, altbough as part of their training both took a share of the house-to-house work which forms an important feature of our sanitary administration in Leeds. From the first all cases of puerperal fever were handed over to them and they looked after the disinfection of the person and clothing of the nurse or midwife who had been in attendance. Betore long we asked them to investigate the house conditions obtaining in autumnal diarrhoea, and as the com. mittee from time to time increased our staff we were able to develop their activities more and more in the second direction indicated in the report.

Now for some four years every death of a child under two 
years of age in a certain district of the town, with a population of about 34,000 , has been investigated by one or another of our staff of six women inspectors. The district chosen was the one in which infant mortality was highest. In the beginning of 1905 we added to their duties the visiting of every house in the same district in which a child had been born, getting the information as to the birth from the local register under the new rule of the Registrar-General; and during the latter part of the same year we have intrusted them largely with the care of infants in the same district, providing them, through the generosity of a voluntary association, with a supply of bottled milk obtained under specially careful supervision.

1 do not propose to say anything more about the duties of the women inspectors in connexion with work-places, except to emphasise the enormous advantage that has accrued to Leeds from that part of their work particularly in connexion with the provision and supervision of sanitary conveniences. Their visits to work-places have enabled them to obtain information about the conditions under which married women in our workshops and to a less extent in our factories are employed. Their visits to houses also, even where simply inquiring into the cause of death of another child, have enabled them to exercise a certain amount of salutary influence in the homes of the district in which they more particularly work. But the chief interest so far as we are at present concerned centres around the assistance rendered in the care of young and living children. Where a birth is reported through the registrar in the particular district to which this part of their work is almost entirely confined, they make inquiries of a more or less general kind into what would be called in a medical report the "family history" of the infant. This inquiry is, of course, more or less for scientific purposes, and so far as it has gone, especially when taken in conjunction with the similar inquiry made in regard to all deaths in the same district occurring in children under two years of age, has thrown considerable light apon the influence of certain circumstances upon the well-being of the child.

It has been made pretty clear to us that the infantile deaths are to a large extent connected with weakness or poverty on the part of the mother. Out of some 1221 cases where we have investigated the family conditions after the death of a young child during the period from April 2nd, 1902 , to April 14th, 1906, it was ascertained that the number born to the same parents had been some 5208, whilst the number of those still alive at the time of our inquiry was only 2582 , or less than half. In addition the same mothers had given birth to 167 stillborn. We have not, as a rule found that, at least in this district, the employment of women before their confinement has been associated very specially with the death of their infants. For instance, in the period already mentioned, of the 1221 cases investigated it was found in 199 , or 16 per cent., that the mother had been engaged in some employment outside her own house before, though not necessarily close up to, the time of confinement, whereas in 1022 cases, or nearly 84 per cent., this was not the case. Similarly, 122 out of the 1221 began to work soon after the child's birth, but in 1099 , or 90 per cent., it was not so. We are rather led to think, although one would naturally not wish a woman to work up to the very time of parturition, that the wage earned by these expectant mothers is perhaps sometimes of considerable value to the health of the coming child and compensates to some extent for the disadvantages of work, at least if the latter be carried on in well-ventilated and carefully cleansed workplaces.

The conditions also of the dwelling-house are themselves of no inconsiderable importance and it is here largely, and especially in regard to cleanliness, that so much can be done in assisting the mothers of the coming race. It is found, as a rule, that if care be taken not to hurt the feelings of those who are visited-if the work be done with tact and discretion-the help we are prepared to offer is welcomed. The new arrivals whom we see are not generally the very youngest and it is here that our work differs in an important manner from the splendid attempt being made in Huddersfield. We rely as a general rule upon the receipt of the information as to the birth from the registrar. The average period from the child's birth to the date of our hearing of it from him we find, during 1905 , to have been 42 days and in a considerable number of cases the birth and the death were registered at the same time; whilst in a few and not altogether inconsiderable number of cases the death of the infant has been actually registered before its birth, so that our visit to the house was in consequence of the death rather than of the birth of the infant. Dealing, however, with the cases of the young children of whose arrival we hear in the way mentioned the woman inspector takes a considerable amount of trouble to persuade the mother of the importance of nursing, or of continuing to nurse, the child herself. This difficulty has presented itself. Whilst, as a rule, in this district the mother is quite willing to nurse her child, she not infreguently finds after she begins to get up and go about that she has not the requisite milk to do so. In some cases where this condition has been threatened our inspectors have persuaded her to take herself the milk provided by the Pure Milk Association already spoken of. This action has been followed in many cases by a great benefit. ${ }^{1}$ We generally find in a very short time the mother begins to have a larger supply of milk for her child and we regard this method of " humanising" cows' milk as by far the best. A small handbill couched in familiar language is given to the mother and its purport explained by the inspector (see Appendix). It serves not so much as an actual instruction as a text opon which she can found her homily.

We have three of these small leaflets. No. 1 emphasises the importance of breast-feeding and points out how it should be regulated. It advises the mother, for instance, to take a cup of milk or gruel shortly before suckling the infant and deprecates for the sake of the child the use of stout, spirits, or beer. It then goes on to explain that the mother's milk may in some cases be advantageously supplemented by the use of a little pure cows' milk and explains in what way cows' milk differs from the mother's milk. This handbill was prepared before we had the present supply of pure milk to offer to the parents, but the mother is advised that any milk to be given to the baby should be obtained as fresh as possible.

In this particular district, unless from the want of breastmilk just spoken of, we have usually not much difficulty in getting the mother to nurse her own infant. But it is, of course, necessary where the child is older, or where, notwithstanding the good intent of the parent, the suckling cannot be actually carried on, that some attention should be given to artificial feeding. Accordingly leaflet No. 2 deals with boiling milk. It will be readily understood from what has just been said about the supply of pure milk that I am not in favour of boiled milk. Boiled milk, however, is better than poisoned milk, and leaflet No. 2 indicates some reasons why milk is found so often to disagree with the baby and explains in what way the milk may be treated so as to render it less likely to injure the child. The manner described is, in fact, that known as pasteurisation, which has this advantage over ordinary boiling, that the lactalbumin of the milk is not necessarily entirely coagulated and lost, and that the phosphates are not, to the same extent as in boiled milk, rendered insoluble. It will, however, be understood that where the mother or the child is getting the pure milk supplied by the Leeds Association leaflet No. 2 is not always given. It is considered on the whole safer to recommend that the milk be taken from the stoppered bottle supplied by the association and that it be placed in the cleansed feeding bottle along with a sufficient quantity of boiled water and a little sugar, thus representing to some extent, but without the sterilisation, the milk provided by certain town councils. The milk these towns supply has these three advantages: that (1) it is sterilised ; that (2) it is supplied in the actual bottles to be used by the child, not therefore requiring to be transferred to the feeding bottle; and that (3) its food value is graduated to suit the infant to be fed. Its disadvantages, as it seems to me, are (1) that it provides sterilised milk, milk therefore deprived wholly or in part of its lact-albumin and in which the phosphates have been rendered largely insoluble; and (2) that the method has not

1 The milk so taken is, in the first place, unwatered; in the second place, it is reasonably clean, having been collected at a farm under careful inspection, cooled and placed in sterilised bottles by the association, and kept stoppered until actually required for use. Its bacterial content as compared with the milk sold in the shops, often the same shops, but also in other shops in the same neighbourhood, is exceedingly small and specially characterised by the absence of the group of bacilli associated with excrementitial matters so largely found in ordinary carelessly collected milk. As the milk is intended not onl for mothers but also for children, the udders of the cows from which for mothers but also for children, the udders of the cows from which it attached to the corporation so as to secure freedom from tuberculosis. 
quite the same educative value. We are trying to teach the mother herself to prepare the milk for the child. We try to explain to her the importance of keeping the milk in a proper place ; the necessity and method, under certain conditions of temperature, of herself sterilising the milk if not that provided by the association, when received; and we try to teach her also the proportion in which cows' milk should be mixed with water and sugar to furnish what the child actually needs.

The third leaflet is intended for distribution where the child is a little older. It represents one or two of the facts about cows' milk and it deals to some extent in a general way with the quantities of milk to be given to the child In all cases it is advised that if the child be ill or ailing medical advice should be sought, and our inspectors in no way assume to themselves, although acting under the immediate supervision of the medical officer of health, any right to prescribe for a child who is ill or to interfere in any way with the advice already given by any medical practitioner in regard to the dieting of a healthy or ailing child. In the bulk of the cases visited by our inspectors no medical man is in attendance. We also try to persuade the mothers that the milk provided by the association is a food and not a medicine and we think that this actual visiting of the children and influencing their diet must in time conduce to a lessening of the high infantile death-rate in this particular district. The difficulties we labour under are that the children are many and the inspectors few ; that even these few have other duties-important duties also-to perform elsewhere.

Amongst the latter, one of some special helpfulness in regard to the work amongst infants has been omitted. Our chief lady inspector is herself a registered midwife and is charged, under the direction of the medical officer of health, with the superintendence of the women upon the register. Her staff assist in the necessary visitation and gain much information serviceable to them in their work amongst infants.

Amongst the conditions that I look upon as desirable in regard to women inspectors are the following :1. That their salaries should be at least those given to the men doing corresponding work. Our women inspectors, who rank as ward inspectors, begin with a salary of $33 s$. a week, rising at the end of two years to $36 s$. and then to $38 s$. This is quite little enough. Our head inspector has the salary of one of our divisional inspectors. 2. That none of the women inspectors should devote her whole time to visiting babies. It is better for her own health that there should be some variety in her work. For this purpose these ladies take their share in house-to-house work and in workshops inspection and in both sets of duties, as well as inquiring into cases of infectious disease in schools and factories, and in dealing with nuisances in the latter they gain information useful to them in their work amongst infants and their mothers. 3. That they should have opportunities of comparing notes and that they should work under a senior inspector of their own sex of some experience. ${ }^{2}$ 4. Lastly, that as women are greedy of work, are self-sacrificing, and often over-estimate their own strength, it is desirable that they should work under medical supervision.

\section{APPENDIX}

Leaflet No. $I$ is printed in two pages, $3 \frac{1}{2}$ inches by 6 incbes. The two pages face one another, and the type is pica. This leaflet is explained by the inspector. Nos. 2 and 3 are intended for the mothers of older children, and of those who cannot be fed naturally. Their sizes are the same. In drawing them up the endeavour to make them sizes are the same. In drawing

$$
\text { CITY of LEEDS. }
$$

The feeding of infants (No. 1).-The best food for the young child is its mother's milk. Nothing but illness on the part of the mother is its mother's milk. Nothing but illness on the part of the mother should have the breast every two hours till it is two months old, then for the third month about every two hours and a half, after that every three hours.

The child should be put to the breast as soon as it is born. The mother's milk quite at first will cause slight purging. This is good for

If suckling is begun from the first the mother will generally have as much milk as the baby needs till it is six months old. The mother may take a cup of milk, milk gruel, or milk and water, half an hour before suckling. It is far better for the child that she should not take

2 I find that ladies when writing to us for information about doing health work - and this was more especially the case at first-inquire if they are to work under the sanitary inspector or the medical officer of health. In many cases an educated woman of the middle classes seems more willing to undertake work under the direct control of a inspector, however able and well informed.
If the mother's milk is not quite sufficient, the child may have a little cows' milk in addition once or twice a day. Cows' milk is stronger in the "casein" which makes the curd. It should, therefore, have a little water added, and, if possible, a little sugar and cream. Skimmed and separated milk, from which all or part of the cream has been removed, should not be given to children at all.

The milk given to the baby should be obtained as fresh as possible. Sanitary Offices, Leeds.

J.S. C.

\section{CATERPILLAR RASH.}

\section{BY JOHN O. THRESH, M.D. VICT., D.Sc. LOND.,}

MEDICAL OFFICER OF HEALTH TO THE ESSEX COUNTY COUNCIL

LECTURER ON PUBLIC HEALTH AT THE IONDON HOSPITAT MEDICAL COLLEGE.

AMONGST entomologists it is quite well known that certain caterpillars cannot be handled with impunity, but that some persons are much more prone to be affected than others. According to Kirby and Spence, ${ }^{1}$ this fact must have been known to the Romans, for after remarking that the hairs of several kinds of moth have much the same effect upon the skin as the hairs of the seeds of Dolchicos pruriens, they add: "Of this nature also is the famous pityocampa of the ancients, the moth of the Cnethocampa pityocampa, the hairs of which are said to occasion a very intense degree of pain, heat, itching, and restlessness. It was accounted by the Romans a very deleterious poison as is evident from the circumstance of the Cornelian law 'De sicariis' being extended to persons who administered pityocampa." In a footnote they add that Dr. Nicholais considered that this caterpillar secreted an irritant juice.

Every few years some entomologist suffers from an urticarial rash due to handling caterpillars or their cocoons and many references are made to this subject in the volumes of the Entomologist. In November, 1884, a correspondent stated that he had been breeding the brown-tailed moth Liparis (or Porthesia) chrysorrhœea and that upon emptying his breeding-cage he was so quickly attacked by intense irritation of the skin that he rushed off to a surgeon. He had a second similar experience which led him to conclude that he was not suffering from simple nettle-rash but a rash due in some way to the Liparis chrysorrboa in the pupa state. Dr. Percy Randall (St. Bartholomew's Hospital) in December attributed this irritation to the hairs which form so large a portion of the cocoons of this moth and added, "Country children, who are in the habit of collecting these larvæ, being attracted by their bright colours, are very subject to it. After carrying them home in their handkerchiefs and aprons, they perhaps wipe their faces and necks and forthwith suffer from an acute attack. The hairs on examination will be found sticking out from the skin." In the same journal an interesting paper appeared (January, 1885) by $R$. South on "Urticating Hairs of some Lepidoptera," in which he referred to the experience of himself and a relative when handling some imagines of Porthesia similis vel Liparis auriflua. Some time afterwards he felt an unpleasant tingling about the eyes, the lids became swollen, and large wheals appeared on his throat and neck. The relative, who had also handled the imagines, was not at all affected. He had previously had an acute urticaria after handling the larvæ of the Bombyx rubri. He mentions also that a species of caterpillar found in Brazil gives rise to unbearable pain, inflammation, and swelling if it falls upon the neck. He also quotes an opinion that the hairs of the larva of Porthesia similis are covered with a poisonous liquid exuded from the scarlet warts on the hinder segment but at the same time suggests that as the hairs of the larvæ of the genus Cnethocampa are barbed they may be the cause of the pain and irritation. In the same issue of the journal is a note quoting a paper by Mr. Dimmock (but where published is not, stated) on Some Glands which Open Externally on Insects. Some tubercles on the larva of Attacus cecropia secrete an odorous liquid acid to litmus. The hairs breal off and an aperture is left in the tubercle through which the liquid exudes. Others think that the liquid is forced through minute apertures in the hairs. Against this theory of an acrid secretion is the experience of persons who have suffered from merely handling the empty cocoons and one case is related in which disagreeable effects resulted from a cocoon which bad been exposed to wind and rain for months.

1 Introduction to Entomology, Section "Direct Injuries caused by Insects. 